\title{
Pulmonary Functions in Patients with End Stage Renal Disease and their Effect after Hemodialysis
}

\author{
Muhammad Anees ${ }^{1}$, Saleem uz Zaman Adhami ${ }^{2}$, Muhammad Aamer ${ }^{3}$ and Imran Shahid ${ }^{1}$ \\ ${ }^{1}$ Department of Nephrology, Shalamar Teaching Hospital, Lahore, Pakistan \\ ${ }^{2}$ Department of Medicine/Pulmonology, Shalamar Medical and Dental College, Lahore, Pakistan \\ ${ }^{3}$ Department of Nephrology, Shalamar Medical and Dental College, Lahore, Pakistan
}

\begin{abstract}
Objective: To determine the pulmonary functions in patients with End Stage Renal Disease (ESRD) and the associated factors including the acute effects of hemodialysis.

Study Design: Observational, cross-sectional study.

Place and Duration of Study: Nephrology Department in collaboration with Pulmonology Department, Shalamar Hospital, Lahore, from October to November 2019.

Methodology: All patients of age 18-75 years, on regular hemodialysis (HD) for more than three months, who quitted smoking 10 years back and stable, were included in the study. Demographic data was collected and blood samples were sent for hematological and biochemical laboratory parameters. Pulmonary functions were assessed by spirometry for Forced Vital Capacity (FVC) and Forced Expiratory Volume in first second (FEV1) and FVC/FEV1 before and after dialysis.

Results: Out of 102 patients, 62 (60.8\%) were males and 79 (77.5\%) were on twice-weekly dialysis. DM $44(43.1 \%)$ and chronic glomerulonephritis 21 (19.5\%) were the major causes of ESRD in these patients. In this study, FVC and FEV1 were abnormal in majority of the patients $73(71.6 \%)$ and $76(74.5 \%)$, which was statistically significant $(p<0.05)$ supporting restrictive lung disease (RLD). Factors associated with RLD were male gender $(p=0.006)$ and diabetes mellitus $(p=0.003)$. Hemodialysis did not improve pulmonary functions significantly. FEV1 and FVC had a negative correlation with age and body mass index (BMI).

Conclusion: Restrictive lung disease is the most common pulmonary dysfunction among ESRD patients. Factors associated with pulmonary dysfunctions were male gender and diabetes mellitus. Hemodialysis did not improve pulmonary functions.
\end{abstract}

Key Words: ESRD, Pulmonary functions, Restrictive lung disease, Fluid overload.

How to cite this article: Anees M, Adhami SUZ, Aamer M, Shahid I. Pulmonary Functions in Patients with End Stage Renal Disease and their Effect after Hemodialysis. J Coll Physicians Surg Pak 2021; 31(02):144-149.

\section{INTRODUCTION}

End Stage Renal Disease (ESRD) is the stage of chronic kidney disease (CKD) when patients need renal replacement therapy in the form of hemodialysis (HD), peritoneal dialysis or renal transplant. Lungs are very important organs, which are affected with this disease. ${ }^{1}$ Factors affecting pulmonary functions are falling hemoglobin level, gas permeability abnormalities, ${ }^{2}$ volume overload, early airway closure, ${ }^{3}$ ventilation perfusion mismatch, decreased oxygen carrying due to hypoventilation, ${ }^{4}$ electrolyte imbalance, malnutrition, metabolic acidosis, ${ }^{5}$ fluid accumulation, ${ }^{6}$ and respiratory muscle weakness. ${ }^{7}$

Correspondence to: Dr. Muhammad Anees, Department of Nephrology, Shalamar Teaching Hospital, Lahore, Pakistan

E-mail:dranees109@hotmail.com

Received: November 29, 2020; Revised: January 18, 2021;

Accepted: February 11, 2021

DOI: https://doi.org/10.29271/jcpsp.2021.02.144
It has been observed that HD improves pulmonary functions as it removes uremic toxins and fluid overload. ${ }^{8,9}$ According to previous studies, ${ }^{10}$ the role of dialysis is limited in improving lung functions. In Pakistan, there is no data available on this subject and internationally few studies have been reported showing conflicting results of pulmonary dysfunctions in patients with HD. So, this study was designed to highlight this important aspect of HD patients.

Theobjective of thisstudy was to determinethe pulmonary functions in patients with ESRD, and the associated factors including the acute effects of HD.

\section{METHODOLOGY}

This observational, cross-sectional study was conducted at HD Centre of Nephrology Department of Shalamar Hospital,Lahore, in collaboration with Pulmonology Department after taking permission from Institutional Review Board of Shalamar Medical and Dental College, Lahore. All patients of age 18-75 years, on regular HD for more than three months, quitted smoking 10 years back, and clinically stable, were included in 
the study. Patients were excluded having history of acute kidney injury (AKI), chronic obstructive pulmonary disease, decompensate heart disease, active smoker and with musculoskeletal disorders. All the patients coming for HD were examined for volume status (peripheral edema, raised jugular venous pressure and chest examination) and body mass index (BMI) measurement by using Mostellar Formula. Demographic data was collected on predesigned proforma including age, gender, education, socio-economic status, duration of ESRD and frequency of HD. Blood samples were sent for hematological (Hemoglobin) and biochemical (Serum urea, creatinine, sodium, potassium, calcium, phosphorus, intact PTH, ferritin and transferrin saturation (TSAT \%) parameters. Kidney Disease Initiative Global Outcome (KDIGO) guidelines were followed for abnormal and normal laboratory parameters. ${ }^{11}$ Patients underwent non-invasive spirometry before dialysis for measurement of FEV1, FVC and FEV1/FVC. On the basis of already laid down criteria, lung functions were divided into normal, RLD and obstructive lung disease (OLD) pattern. ${ }^{12}$ Patients were hooked up with dialysis machine (Fresenius Medical Care 4008-B) for four hours. Dialysis prescription was documented including ultra-filtration rate $(\mathrm{ml} / \mathrm{min})$, blood flow rate $(\mathrm{QB}=\mathrm{ml} / \mathrm{min})$, dialysate flow rate $(\mathrm{QD}=\mathrm{ml} / \mathrm{min})$, heparin usage, polysulfone membrane capillary dialyser (Fresenius FX10); and standard bicarbonate dialysis solution was used in all patients. After the completion of four-hour dialysis session, pulmonary functions were reassessed by spirometry and recoded.

Statistical analysis was done using SPSS (SPSS version 22.0, SPSS Inc. Chicago, IL, USA) software. Descriptive statistics was done using summary measures for categorical variables as well as continuous variables. For categorical variables, i.e. gender, smokers, RLD, OLD and mixed lung disease, percentages (proportion) were used. For continuous variables, e.g. age, duration of ESRD, mean and standard deviation were reported. Data was stratified for age, gender, and duration of ESRD. Chi-square test/Fishers Exact test was used to determine any association between categorical variables as per requirement of the data. Pearson correlation coefficient was also employed to determine the relationship among continuous variables. Paired t-test was used to compare PFT's (Predicted, pre-dialysis and post-dialysis). Logestic regression was used as multivariate analysis to determine the effect of BMI and cause of ESRD on RLD in HD patients. A p-value $\leq 0.05$ was considered as statistically significant.

\section{RESULTS}

One hundred and sixty patients on regular HD were enrolled, among them 102 patients were included in the study who fulfilled the inclusion criteria. The patient's average age was $50.91 \pm 13.55$ years. Most of the patients were males 62 $(60.8 \%)$, with less than $10^{\text {th }}$ grade education $31(30.4 \%)$, and on twice-weekly dialysis 79 (77.5\%). Diabetes mellitus 44 (43.1\%) and chronic glomerulonephritis 21 (19.5\%) were major causes of ESRD. Mean hemoglobin was $10.34 \pm 1.85 \mathrm{gm} / \mathrm{dl}$ and majority of the patients $64(62.7 \%)$ were anemic $(\mathrm{Hb}<11 \mathrm{~g}$ $\mathrm{m} / \mathrm{dl}$ ) and having adequate iron (TSAT >20\%) 71 (69.6\%) for hemoglobin synthesis. The normal predicted spirometric parameters (based on BMI,age and gender) were calculated by Spirometer. Pre and post dialysis spirometric parameters were also noted as shown in Table I and II. In this study, FVC and FEV1 were found abnormal in majority of the patients 73 (71.6\%) and $76(74.5 \%)$ which was statistically significant $(p<0.05)$ showing RLD is most common in ESRD patients. High FVC and FEV1 with normal ratio ( $>70 \%$ ) of FEV1/FVC in most of the patients $83(81.4 \%)$ showed that OLD is not common in these patients. Factors associated with RLD were male gender $(p=0.006)$ and DM as cause of ESRD $(p=0.003)$ as shown in Table III. HD did not improve pulmonary functions as shown in Table II. FEV1 and FVC have negative correlation with age and BMI $(r=-0.233, p=0.018, r=-0.201, p=0.042, r=-0.223$, $p=0.024, r=-0.233, p=0.019$ ), respectively as shown in Figure 1 . According to logestic regression analysis, factors affecting PFTs were DM as cause of $\operatorname{ERSD}[\operatorname{Exp}(\beta)=0.585, p=0.002]$ and $\operatorname{BMI}[\operatorname{Exp}(\beta)=2.038, p=0.085]$.

\section{DISCUSSION}

Kidney failure reduces pulmonary mechanical and ventilatory functions. RLDs are characterised by reduced lung volume due to changes in lung parenchyma, stiff chest walls and neuromuscular disorders. RLD is the most common pulmonary dysfunction in patients on HD, peritoneal dialysis, and among renal transplant patients affecting morbidity and mortality. ${ }^{13}$ In this study, most common pulmonary dysfunction was RLD in majority of the patients. Similar pattern of RLD in patients with ESRD is reported in other studies from the neighboring countries like India $(82 \%),{ }^{8}$ which is much higher than developed country like China, where it was only $64 \% .{ }^{14}$ Same pattern of RLD was observed in a local study by Anees et al. in patients who were not on dialysis. ${ }^{15}$ According to this study, RLD was statistically significant in patients with GFR less than $15 \mathrm{ml} / \mathrm{min} / 1.73 \mathrm{~m}^{2}$ than patients with higher GFR. So, progression of CKD was associated with derangements of pulmonary functions. There are many reasons for RLD in patients with ESRD like increased extra-vascular lung volume, left ventricular hypertrophy, metastatic lung calcification, iron deposition, pleural effusion and pulmonary hypertension ${ }^{16}$ Uremia not only affects overall functions of all organs of the body but severely affects respiratory muscle like diaphragm and inter-costal muscles. According to Tarasuik et al, severe uremia may be the cause of decrease in muscle strength, causing ventilatory defect leading to decline of all parameters of the lungs. ${ }^{7}$ Along with all these factors, late referral to nephrologists and inadequate dialysis are additional probable factors, which may affect pulmonary functions. ${ }^{17,18}$ Due to underdeveloped specialty of nephrology, patients of ESRD are being managed by alternative methods of treatment in the form of herbal, spiritual and homeopathic ways; and present to nephrologists just at the verge of dialysis having advanced complications of uremia. 
Table I: Predicted and actual pulmonary functions of the ESRD patients.

\begin{tabular}{|l|c|c|c|}
\hline Pulmonary functions & Predicted value based on age, gender and BMI & Actual value of the ESRD patients & p-value \\
\hline FEV1 (litter) & $2.51 \pm 0.66$ & $1.75 \pm 0.44$ \\
\hline FVC (litter) & $3.02 \pm 0.83$ & $<0.001 *$ \\
\hline FEV1/FVC (litter) & $83.01 \pm 3.06$ & $1.72 \pm 0.45$ \\
\hline *Statistically significant value & & $<0.001 *$ \\
\hline
\end{tabular}

Table II: Comparison of pre- and post-HD pulmonary functions tests $(n=102)$.

\begin{tabular}{|l|c|c|c|}
\hline Pulmonary function & Pre-HD & Post-HD & p-value \\
\hline FEV1 (litter) & $1.59 \pm 0.68$ & $1.53 \pm 0.73$ & 0.138 \\
\hline FVC (litter) & $2.00 \pm 0.89$ & $2.00 \pm 0.96$ & 0.966 \\
\hline FEV1/FVC (litter) & $81.46 \pm 11.71$ & $78.95 \pm 14.33$ & 0.067 \\
\hline
\end{tabular}

Table III: Factors associated with pulmonary functions in patients with HD $(n=102)$.

\begin{tabular}{|c|c|c|c|}
\hline Parameters & $\begin{array}{c}\text { Normal lungs } \\
\text { function } \\
\text { (frequency \%) }\end{array}$ & $\begin{array}{c}\text { Restrictive lungs } \\
\text { disease } \\
\text { frequency (\%) }\end{array}$ & p-value \\
\hline $\begin{array}{l}\text { Gender } \\
\text { Male } \\
\text { Female }\end{array}$ & $\begin{array}{c}21(20.6 \%) \\
4(3.9 \%)\end{array}$ & $\begin{array}{l}41(40.2 \%) \\
36(35.3 \%)\end{array}$ & 0.006* \\
\hline $\begin{array}{l}\text { Age (year) } \\
<45 \\
>45\end{array}$ & $\begin{array}{l}11(10.8 \%) \\
14(13.7 \%)\end{array}$ & $\begin{array}{c}28(27.5 \%) \\
49(48 \%)\end{array}$ & 0.495 \\
\hline $\begin{array}{l}\text { Cause of ESRD } \\
\text { DM } \\
\text { HTN } \\
\text { Chronic glomerulonephritis } \\
\text { Unknown causes } \\
\text { Nephrolithiasis }\end{array}$ & $\begin{array}{l}6(5.9 \%) \\
8(7.8 \%) \\
8(7.8 \%) \\
2(2.0 \%) \\
7(6.9 \%)\end{array}$ & $\begin{array}{c}38(37.3 \%) \\
10(9.8 \%) \\
13(12.7 \%) \\
7(6.9 \%) \\
3(2.9 \%)\end{array}$ & $0.003 *$ \\
\hline $\begin{array}{l}\text { Frequency of dialysis } \\
\text { Twice week } \\
\text { Thrice week }\end{array}$ & $\begin{array}{c}19(18.6 \%) \\
6(5.9 \%)\end{array}$ & $\begin{array}{l}60(58.8 \%) \\
17(16.7 \%)\end{array}$ & 0.842 \\
\hline $\begin{array}{l}\text { BMI }\left(\mathrm{kg} / \mathrm{m}^{2}\right) \\
\text { Normal } 18.5-24.9 \\
\text { Underweight }(<18.5) \\
\text { Overfweight/obese }(>25)\end{array}$ & $\begin{array}{c}16(15.7 \%) \\
2(2.0 \%) \\
7(6.9 \%) \\
\end{array}$ & $\begin{array}{c}43(42.2 \%) \\
4(3.9 \%) \\
30(29.4 \%) \\
\end{array}$ & 0.574 \\
\hline $\begin{array}{l}\text { Interdialysis weight gain } \\
<1000 \mathrm{Kg} \\
>1000 \mathrm{Kg}\end{array}$ & $\begin{array}{c}1(1.0 \%) \\
24(23.5 \%)\end{array}$ & $\begin{array}{l}16(15.7 \%) \\
61(59.8 \%)\end{array}$ & 0.064 \\
\hline
\end{tabular}

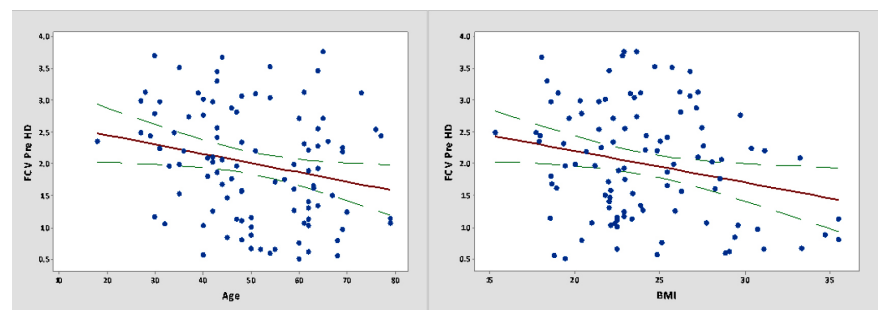

Figure 1 (a): Correlation of pulmonary function (FCV) with age and BMI.

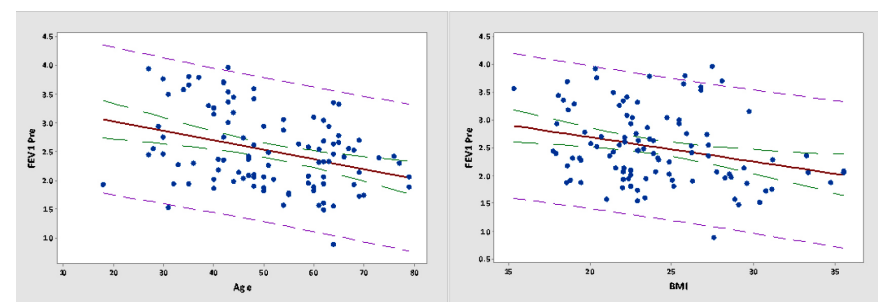

Figure 1 (b): Correlation of pulmonary function (FEVI) with age and BMI.

The prolonged exposure of these patients to uremic toxins leads to pulmonary dysfunctions in the form of RLD. As the treatment of ESRD is very expensive in the form of dialysis and medications, which cannot be afforded by most of the patients and they get inadequate dialysis in the form of twice weekly dialysis leading to permanent damage of the lungs and leading to RLD. Along with inadequate dialysis, low flux dialysers were used in the patients, which removed uremic toxins less efficiently than dialysers used with high flux dialysis, ${ }^{14}$ exacerbating RLD in these patients.

Gender plays a major role in both the healthy and diseased lung since childhood. Gender also impacts airway inflammation and the prevalence and severity of many major lung diseases including pulmonary fibrosis, asthma and lungs cancer. In this study, conducted at Lahore, male HD patients were more prone to develop pulmonary dysfunctions than female patients, which is not in accordance with international literature favouring female preponderance. ${ }^{19}$ Similar observation showing male preponderance affecting pulmonary dysfunction was made from Faisalabad, but it was 
conducted on general population and not on HD patients. ${ }^{20}$ According to World Air Quality Report 2018, Pakistan was the second most polluted country in the world. At the time of writing of this article, air quality in Lahore on most of the days is 200-300US AQI. This shows that urbanisation and heavy traffic load producing smoke are important risk factors for pulmonary diseases. Pakistan's air pollution levels have transformed into a more dire health emergency than smoking, tuberculosis and cardiovascular diseases, reducing life expectancy. Due to poverty, most of the men travel by motorbikes and exposed themselves to air pollution than women, staying at home. Cigarette smoking is also more prevalent in males than in female (already patients of CKD) population causing pulmonary dysfunction.

In this study, HD patients with DM were having more RLD than non-diabetic patients. DM is a syndrome affecting head-to-toe, and lungs are one of the important organs in these patients. ${ }^{21}$ Even patients having DM without kidney involvement are having high prevalence of RLD than non-DM patients. According to Dennis et al., RLD was present in $27 \%$ of patient with long term type 2 diabetes mellitus, in $20 \%$ of patients with newly diagnosed diabetes, and $9 \%$ of the patients with pre-diabetes. ${ }^{22}$ Diabetes mellitus is associated with increased levels of systemic inflammatory mediators and markers, which together with microangiopathy, are accused in alterations of lung matrix proteins; and hence, the impairment of pulmonary functions. It is likely that persistent inadequate blood glucose control over time may alter the regulation of inflammatory pathways that are involved in pulmonary function impairment; this impairment is mainly restrictive leading to reduction in diffusing capacity to carbon monoxide.

Patients on dialysis are mostly oliguric or anuric and they gain weight in the inter-dialysis period. Excessive inter dialysis weight gain is serious problem in patients with ESRD. The fluid overload increases the permeability of the pulmonary capillaries and transfer of fluid to interstitium, causing interstitial edema which manifests as restrictive ventilation dysfunction. In this study, statistically significant factor causing RLD was volume overload, and pulmonary edema as observed by another study. FVC, FVC\%, FEV1, FEV1\%, mean forced expiratory flow between $25 \%$ and $75 \%$ of the FVC (FEF25-75), FEF25-75\%, peak expiratory flow rate (PEFR), and PEFR\% were found to be significantly lower in patients with fluid overload than in those without. $^{6}$ As Pakistan is present on equator, and especially in hot weather, patient inter dialysis weight gain is very high. Even after repeated advice by dialysis staff and nephrologists, these patients take lot of fluids. This chronic volume overload stage ends up with RLD. Another reason is that due to financial constraints and non-availability of dialysis slot, most of the patients get twice weekly dialysis making it difficult to remove excess fluid and even with ultra-filtration during HD, these patients remain in the stage of over hydration all the times leading to chronic pulmonary congestion and RLD.

In this study, pulmonary functions of patients did not improve after HD. Similar observation was made by El Wahsha and there was no significant difference between pre HD and post HD pulmonary function. ${ }^{23}$ Almost same observation was made by Rayhamed et al. ${ }^{24}$ Only FVC improved after HD, while there was no significant improvement in FEV1 and FEV1/FVC. But there are studies which showed significant improvement in pulmonary functions of HD patients. ${ }^{11}$ According to Sharma et al. ${ }^{8}$ patients pre-dialysis mean FVC and FEV1 improved significantly after HD. The probable reason of not improving pulmonary functions may be that lungs are so badly damaged in these patients that HD did not improve them. Other reason of not improving the lung functions may be that as most of the patients were having abnormal BMI (obese and underweight) and exhausted after getting four hour dialysis due to which they cannot perform properly pulmonary functions.

It has been observed that with increasing age, there are reductions in physiological capacity, including ventilatory control, respiratory muscle strength, respiratory mechanics and gas exchange. In this study, FEV1 and FVC have negative correlation with age in patients with HD. It has been observed that with increasing age, there is a progressive increase in the rigidity of the chest wall and decrease in the elastic recoil of the lung. Many studies have shown that increasing age is independently associated with a reduction in both the maximal inspiratory pressure, a measure of inspiratory muscle strength and the maximal expiratory pressure, a measure of expiratory muscle strength. Increased visceral fat mass is linked to metabolic syndrome associated with asthma and impaired lung functions in adolescents and adults. In this study, FEV1 and FVC have negative correlation with BMI. Similar observation was made by Schachter LM et al. ${ }^{25}$ Mechanical properties of the lung and chest wall are significantly altered in obesity largely due to fat deposition in mediastinum and cavities. These changes reduce the compliance of the lungs, chest wall and entire respiratory system.

The limitations of the study are that it is a single-centre cross-sectional study. It should be extended to make a multi-centric study for more valid results. There is need to conduct a longitudinal prospective study and enroll patients before first dialysis and follow-up to observe the significant effect of dialysis on pulmonary functions.

\section{CONCLUSION}

Pulmonary dysfunctions are common among ESRD patients. Most common pattern of pulmonary dysfunction is RLD. Factors associated with pulmonary dysfunctions are male gender and DM as cause of ESRD. HD does not improve pulmonary functions.

ETHICAL APPROVAL:

The study was approved by the IRB of Shalamar Medical and 
Dental College, Lahore. (No. 0148, Dated $24^{\text {th }}$ October 2019).

\section{PATIENTS' CONSENT:}

Informed consents were obtained from all patients included in the study.

\section{CONFLICT OF INTEREST:}

The authors declared no conflict of interest.

\section{AUTHORS' CONTRIBUTION:}

MA: Main idea, conceptual framework, data acquisition and analysis, final writeup.

SZA: Supervision of pulmonary function tests and final revision.

MA: Literature review and critical revision.

IS: Data collection.

\section{REFERENCES}

1. Rezaeetalab F, Zeraati A, Fadaeian AH, Akbarirad M, Azami G, Lari SSM, et al. Spirometric parameters: Hemodialysis compared to peritoneal dialysis. J Cardio-Thoracic Med 2015; 3(2):293-96. 10.22038/JCTM.2015.4376

2. Wallin CJB, Jacobson SH, Leksell LG. Subclinical pulmonary oedema and intermittent haemodialysis. Nephrol Dial Transplant 1996; 11(11):2269-75. doi: 10.1093/oxford journals.ndt.a027147.

3. Ralph DD, Ott SM, Sherrard DJ, Hlastala MP. Inert gas analysis of ventilation-perfusion matching during hemodialysis. J Clin Invest 1984; 73(5):1385-91. doi: 10.1172/JCI111342.

4. Senatore M, Buemi M, Di Somma A, Sapio C, Gallo GC. Respiratory function abnormalities in uremic patients. $G$ Ital di Nefrol organo Uff della Soc Ital di Nefrol 2004; 21(1): 29-33.

5. Kovelis D, Pitta F, Probst VS, Peres CPA, Delfino VDA, Mocelin AJ, et al. Pulmonary function and respiratory muscle strength in chronic renal failure patients on hemodialysis. J Bras Pneumol 2008; 34(11):907-12. doi: 10.1590/s1806-37132008001100004.

6. Yilmaz S, Yildirim Y, Yilmaz Z, Kara AV, Taylan M, Demir M, et al. Pulmonary function in patients with end-stage renal disease: Effects of hemodialysis and fluid overload. Med Sci Monit 2016; 22:2779-84. doi: 10.12659/msm.897480.

7. Tarasuik A, Heimer D, Bark H. Effect of chronic renal failure on skeletal and diaphragmatic muscle contraction. Am Rev Respir Dis 1992; 146(6):1383-8. doi: 10.1164/ajrccm/ 146.6.1383.

8. Sharma A, Sharma A, Gahlot S, Prasher PK. A study of pulmonary function in end-stage renal disease patients on hemodialysis: A cross-sectional study. Sao Paulo Med J 2017; 135(6):568-72. doi: 10.1590/1516-3180.2017. 0179150817.

9. Hasan AM, Alashkar AM, Esmael NF, Ibrahim AAE. Assessment of pulmonary function in end stage renal disease patients on regular hemodialysis. Egypt J Hosp Med 2019; 76(1):3319-23. DOI: 10.12816/ejhm.2019.36895.

10. Lang SM, Becker A, Fischer R, Huber RM, Schiffl H. Acute effects of hemodialysis on lung function in patients with end-stage renal disease. Wien Klin Wochenschr 2006; 118(3-4):108-13. doi: 10.1007/s00508-006-0564-7.

11. KDIGO. Erratum: Kidney disease: Improving global outcomes (KDIGO) CKD-MBD update work group. KDIGO 2017 Clinical practice guideline update for the diagnosis, evaluation, prevention, and treatment of chronic kidney disease - mineral and bone disorder (CKD-MBD). Kidney Int Supp/ 2017; 7(3):e1. doi: 10.1016/j.kisu.2017.10.001.

12. Rabe KF, Hurd S, Anzueto A, Barnes PJ, Buist SA, Calverley $P$, et al. Global strategy for the diagnosis, management, and prevention of chronic obstructive pulmonary disease: GOLD executive summary. Am J Respir Crit Care Med 2007; 176(6):532-55. doi: 10.1164/rccm.200703-456SO.

13. Mukai $H$, Ming $P$, Lindholm $B$, Heimbürger $O$, Barany $P$, Stenvinkel $P$, Qureshi AR. Lung dysfunction and mortality in patients with chronic kidney disease. Kidney Blood Press Res 2018; 43(2):522-35. doi: 10.1159/00048869914.

14. Lin $\mathrm{H}$, Wu YG, Zhang JH, Kan M. High-flux dialysis improves pulmonary ventilation function in uremic patients. Mol Med Rep 2013; 7(5):1603-6. doi: 10.3892/mmr.2013.1373.

15. Anees M, Akbar H, Ibrahim M, Saeed MS, Ismail M. Pulmonary functions and factors affecting them in patients with chronic kidney disease. J Coll Physician Surg Pak 2020; 30(10):1082-5. doi: 10.29271/jcpsp.2020.10.1082.

16. Abdalla ME, AbdElgawad M, Alnahal A. Evaluation of pulmonary function in renal transplant recipients and chronic renal failure patients undergoing maintenance hemodialysis. Egypt J Chest Dis Tuberc 2013; 62(1):145-50. doi.org/10.1016/j.ejcdt.2013.04.012

17. Anees M, Mumtaz A, Nazir M, Ibrahim M, Rizwan SM, Kausar T. Referral pattern fof hemodialysis patients to nephrologists. J Coll Physicians Surg Pak 2007; 17(11): 671-674. doi.org/11.2007/JCPSP.671674.

18. Anees M, Aizaz M, Waqaw A TS. Adequecy of hemodialysis. 2002. J Coll Physician Surg Pak 2002; 12(11):692-5.

19. Pinkerton KE, Harbaugh M, Han MK, Le Saux CJ, Van Winkle LS, Martin WJ, et al. Women and lung disease. Sex differences and global health disparities. Am J Respir Crit Care Med 2015; 192(1):11-16. doi:10.1164/rccm. 2014091740PP.

20. Tayyaba S, Aqsa A,Salma S, Khalid A, Tehniat S, Zahra J, et al. Epidemiological estimates of respiratory diseases in the hospital population, Faisalabad, Pakistan. Braz Arch Biol Technol 2017; 60:e17160358. doi.org/10.1590/ 1678-4324-2017160358.

21. El-Azeem AA, Hamdy G, Amin M, Rashad A. Pulmonary function changes in diabetic lung. Egypt J Chest Dis Tuberc 2013; 62(3):513-7. doi.org/10.1016/j.ejcdt.2013.07.006.

22. Dennis RJ, Maldonado D, Rojas MX, Aschner P, Rondón M, Charry $L$, et al. Inadequate glucose control in type 2 diabetes is associated with impaired lung function and systemic inflammation: A cross-sectional study. BMC Pulm Med 2010; 26:10:38. doi: 10.1186/1471-2466-10-38.

23. El Wahsh R, Zaki A. Pleuro-pulmonary changes in patients suffering from end-stage renal disease receiving regular hemodialysis. Eur Respir J 2011; 38(Suppl 55):p3617. http://erj.ersjournals.com/content/38/Suppl_55/p3617.

24. Rahgoshai R, Rahgoshai R, Khosraviani A, Nasiri AA, Solouki 
M. Acute effects of hemodialysis on pulmonary function in patients with end-stage renal disease. Iran J Kidney Dis 2010; 4(3):214-7.
25. Schachter LM, Salome CM, Peat JK, Woolcock AJ. Obesity is a risk for asthma and wheeze but not airway hyper-responsiveness. Thorax 2001; 56(1):4-8.

$\bullet \bullet \bullet \bullet \bullet \bullet \bullet \bullet \bullet$ 